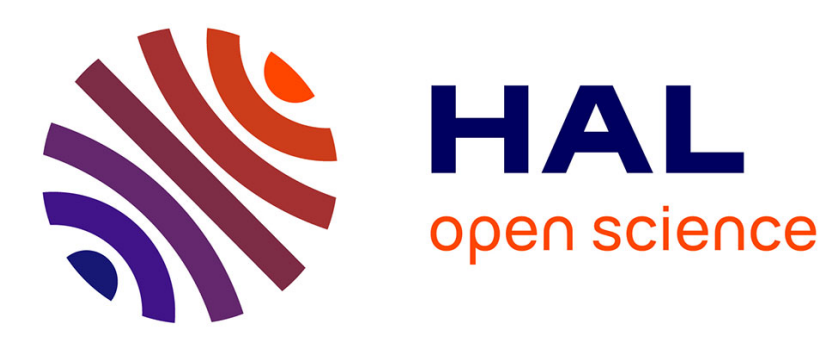

\title{
Physically-based preconditioner for the WCIP
}

Nathalie Raveu, Julien Vincent, Jean-René Poirier, Ronan Perrussel, Luc

Giraud

\section{To cite this version:}

Nathalie Raveu, Julien Vincent, Jean-René Poirier, Ronan Perrussel, Luc Giraud. Physically-based preconditioner for the WCIP. Asia-Pacific Microwave Conference (APMC 2012), Dec 2012, Kaohsiung, Taiwan. pp. 1310 - 1312, 10.1109/APMC.2012.6421905 . hal-00907360

\section{HAL Id: hal-00907360 \\ https://hal.science/hal-00907360}

Submitted on 21 Nov 2013

HAL is a multi-disciplinary open access archive for the deposit and dissemination of scientific research documents, whether they are published or not. The documents may come from teaching and research institutions in France or abroad, or from public or private research centers.
L'archive ouverte pluridisciplinaire HAL, est destinée au dépôt et à la diffusion de documents scientifiques de niveau recherche, publiés ou non, émanant des établissements d'enseignement et de recherche français ou étrangers, des laboratoires publics ou privés. 


\title{
Physically-based Preconditioner for the WCIP
}

\author{
N. Raveu ${ }^{\#}$, J. Vincent*, J.-R. Poirier ${ }^{\#}$, R. Perrussel ${ }^{\#}$, L.Giraud ${ }^{\&}$ \\ ${ }^{\#}$ Université de Toulouse, INPT, CNRS, Laplace, 2 rue Charles Camichel, Toulouse, France \\ *Electromagnetic and Radar Department, ONERA, Toulouse, France \\ ${ }^{\&}$ Inria Bordeaux-Sud Ouest, joint Inria-CERFACS lab.
}

\begin{abstract}
A physically-based preconditioner for the 1d and 2d Wave Concept Iterative Procedure is introduced in this paper. Numerical results are provided to assess the efficiency of this technique.
\end{abstract}

Index Terms -Preconditioner, WCIP, modal method, multilayered planar circuit.

\section{INTRODUCTION}

The Wave Concept Iterative Procedure (WCIP) is a moment/modal method based on the wave concept [1]-[2] well suited for multilayered planar circuits. The initial scheme may be interpreted as a Richardson iteration for which the convergence is guaranteed but this convergence can be slow. In a previous work, several improvements were presented such as Krylov subspace acceleration [3]. In this paper, a physically-based right preconditioner is introduced. This preconditioner is first developed and analyzed for $1 \mathrm{~d} \mathrm{TE}$ and TM problems such as electromagnetic fields scattered by metallic surfaces printed over different dielectric substrate. This preconditioner contains two variable parameters optimized for the TE and TM case. Finally the same preconditioner is extended to the $2 \mathrm{~d}$ case on an example.

\section{1D WCIP METHOD}

The method is implemented on a $1 \mathrm{~d}$ model circuit with one meshed surface separating two homogeneous media as represented on Fig. 1. In this particular case, a z-invariance is assumed. As a consequence, TE $\left(\mathrm{E}_{\mathrm{y}}=0\right)$ and TM $\left(\mathrm{H}_{\mathrm{y}}=0\right)$ modes are physically separated: if the source is polarized along $\mathrm{z}$, only TE modes are generated, while if the source is polarized along $x$ only TM modes are generated. The method is based on incident $\mathrm{Bi}$ and reflected $\mathrm{Ai}$ waves on the interface (where i stands for media numbered 1 or 2 in Fig. 1). These waves are defined by

$$
\left\{\begin{array}{l}
\mathbf{A}_{\mathrm{i}}=\frac{1}{2 \sqrt{\mathbf{Z}_{0}}}\left(\mathbf{E}_{\mathrm{Ti}}+\mathbf{Z}_{0} \mathbf{H}_{\mathrm{Ti}} \wedge \mathbf{n}_{\mathrm{i}}\right), \\
\mathbf{B}_{\mathrm{i}}=\frac{1}{2 \sqrt{\mathbf{Z}_{0}}}\left(\mathbf{E}_{\mathrm{Ti}}-\mathbf{Z}_{0} \mathbf{H}_{\mathrm{Ti}} \wedge \mathbf{n}_{\mathrm{i}}\right),
\end{array}\right.
$$

with $\mathrm{Z}_{0}$ an arbitrary impedance, $\mathrm{E}_{\mathrm{Ti}}, \mathrm{H}_{\mathrm{Ti}}$ and $\mathrm{n}_{\mathrm{i}}$ the electric, magnetic tangential fields and unit normal outward vector to the surface.

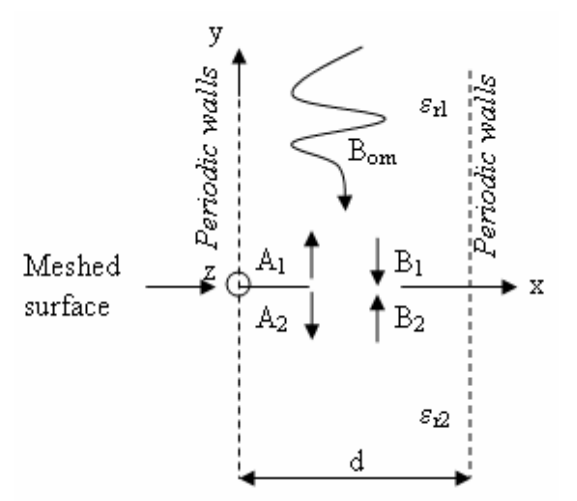

Fig. 1.Example of a $1 \mathrm{~d}$ circuit.

\section{A-Principles}

Interface conditions (metallic or insulate) over the meshed surface are applied on each mesh through a spatial operator S:

$$
\mathbf{A}=\mathbf{S B} \text {, where } \mathbf{B}=\left(\begin{array}{ll}
\mathbf{B}_{1} & \mathbf{B}_{2}
\end{array}\right)^{\mathrm{T}} \text { and } \mathbf{A}=\left(\begin{array}{ll}
\mathbf{A}_{1} & \mathbf{A}_{2}
\end{array}\right)^{\mathrm{T}} .
$$

The homogeneous medium numbered i surrounding the surface is characterized through the modal operator $\Gamma_{\mathbf{i}}^{\alpha}$ defined [1]-[2] ( $\alpha=$ TE or TM) by

$\mathbf{B}=\left(\begin{array}{cc}\Gamma_{1}^{\alpha} & \mathbf{0} \\ \mathbf{0} & \Gamma_{2}^{\alpha}\end{array}\right) \mathbf{A}=\Gamma^{\alpha} \mathbf{A}$

Conversion between the modal and spatial domains is performed through a Fast Modal Transform (FMT) and its inverse $\left(\mathrm{FMT}^{-1}\right)$. Modal sources are expressed through a known $\mathrm{B}_{\mathrm{om}}$ vector added in equation (2). Consequently, the system to be solved is

$$
\left(\mathrm{I}-\Gamma^{\alpha} \mathbf{V S V}^{-1}\right) \mathbf{B}=\mathbf{M B}=\mathbf{B}_{\text {om }}
$$

where $\mathbf{V}=\left(\begin{array}{cc}\text { FMT } & \mathbf{0} \\ \mathbf{0} & \text { FMT }\end{array}\right)$

\section{B-Preconditioner}

An ideal right preconditioner $\mathrm{P}^{-1}$ should be close to $\mathrm{M}^{-1}$, since if $\mathrm{MP}^{-1}$ is close to the identity, the convergence of the iterative scheme is improved. The system to solve is then 
$\mathrm{MP}^{-1} \mathbf{y}=\mathbf{B}_{\text {om }}$.

From the analytic solution in the perfectly conducting and insulating surface, a generic right preconditioner is determined and implemented. For a perfectly conducting case, $\mathrm{S}$ operator is equal to $-\mathrm{I}$, which entails equation (4) becomes simply

$\left(\mathrm{I}+\Gamma^{\alpha}\right) \mathbf{B}=\mathbf{B}_{\text {om }} \cdot$

Therefore $\mathbf{P}=\left(\mathbf{I}+\left(\begin{array}{cc}\Gamma_{1}^{\alpha} & \mathbf{0} \\ \mathbf{0} & \Gamma_{2}^{\alpha}\end{array}\right)\right)$

For a perfectly insulating surface, waves are directly transmitted to the other medium, implying equation (4) becomes

$\left(\mathrm{I}-\Gamma^{\alpha} \mathbf{V}\left(\begin{array}{ll}\mathbf{0} & \mathbf{I} \\ \mathbf{I} & \mathbf{0}\end{array}\right) \mathbf{V}^{-1}\right) \mathbf{B}=\left(\mathbf{I}-\left(\begin{array}{cc}\mathbf{0} & \Gamma_{1}^{\alpha} \\ \Gamma_{2}^{\alpha} & \mathbf{0}\end{array}\right)\right) \mathbf{B}=\mathbf{B}_{\mathrm{om}}$.

Therefore $\mathbf{P}=\left(\mathbf{I}-\left(\begin{array}{cc}\mathbf{0} & \Gamma_{1}^{\alpha} \\ \Gamma_{2}^{\alpha} & \mathbf{0}\end{array}\right)\right)$

Finally, a right preconditioner is assumed with adjustable values $\left(a_{1}, a_{2}\right)$ depending on the circuit shape:

$\mathbf{P}=\left(\mathbf{I}+\left(\begin{array}{cc}\mathbf{a}_{1} \Gamma_{1}^{\alpha} & \mathbf{a}_{2} \Gamma_{1}^{\alpha} \\ \mathbf{a}_{2} \Gamma_{2}^{\alpha} & \mathbf{a}_{1} \Gamma_{2}^{\alpha}\end{array}\right)\right)$

For instance, in the perfectly conducting surface $\left(\mathrm{a}_{1}\right.$, $\left.a_{2}\right)=(1,0)$ is chosen while $(0,-1)$ corresponds to the insulating surface.

\section{NUMERICAL RESULTS}

The surface is meshed into 400 cells, distance between periodic walls is $0.07 \mathrm{~m}$, source is composed of 20 modes. Results are presented as function of the mode type (TE or $\mathrm{TM}$ ), the proportion of metal, the relative permittivity around the meshed surface. GMRes [4] tolerance is set to $10^{-9}$, no restart is used and maximum iteration is set to 400 .

\section{A-Sensitivity to Metal/Insulate proportions}

Iteration number (Niter) is given for several insulate/metal proportion at $300 \mathrm{MHz}$ in the TE case with and without the preconditioner in Table I for the best $\left(a_{1}, a_{2}\right)$ within $[-1,1]^{2}$. Similar results are observed in the TM case. To compare preconditioner costs in computation time 10000 iterations are achieved in the case of Table I for $50 \%$ of metal. One iteration lasts $0.12 \mathrm{~ms}$ without preconditioner and $0.15 \mathrm{~ms}$ with the preconditioner (same results in the TM case). Consequently the decrease in the number of iterations reported in the tables below translates in comparable computational time reduction.

\begin{tabular}{|c|c|c|c|c|c|c|}
\hline \multicolumn{2}{|c|}{ Metal proportion } & $0 \%$ & $25 \%$ & $50 \%$ & $75 \%$ & $100 \%$ \\
\hline \multirow{2}{*}{ 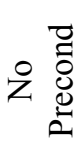 } & Niter & 41 & 96 & 96 & 96 & 21 \\
\hline & $\begin{array}{c}\text { CPU } \\
\text { time }(\mathrm{ms})\end{array}$ & 148 & 704 & 703 & 688 & 55 \\
\hline \multirow{3}{*}{$\begin{array}{l}\vec{Z} \\
0 \\
0 \\
0 \\
0\end{array}$} & $\begin{array}{c}\text { best } \\
\left(a_{1}, a_{2}\right)\end{array}$ & $(0,-1)$ & $(0,-1)$ & $(0,-1)$ & $(0,-1)$ & $(1,0)$ \\
\hline & Niter & 1 & 36 & 45 & 52 & 1 \\
\hline & $\begin{array}{c}\mathrm{CPU} \\
\text { time }(\mathrm{ms})\end{array}$ & 0.15 & 141 & 187 & 238 & 0.15 \\
\hline \multicolumn{2}{|c|}{$\begin{array}{c}\text { Reduction factor } \\
\text { Niter }\end{array}$} & 41 & 2.66 & 2.13 & 1.84 & 21 \\
\hline \multicolumn{2}{|c|}{$\begin{array}{c}\text { Reduction factor } \\
\text { CPU }\end{array}$} & 986 & 4.99 & 3.75 & 2.89 & 366 \\
\hline
\end{tabular}

TABLE I: ITERATION NUMBER FOR SEVERAL METAL PROPORTIONS.

The number of iterations is at least divided at least by 1.8 . Computation time is also reduced. Best couple $\left(a_{1}, a_{2}\right)$ does not depend on the metal/insulate proportion but on the type of the excited modes (except for the perfectly insulate or metallic canonical cases). Many examples were tested and the best solutions for TE and TM problems are respectively $(0,-1)$ and $(1,0)$ whatever the frequency, the substrate permittivity and the metal/insulate proportion (except for the canonical cases: $100 \%$ metal or $100 \%$ insulate).

\section{B-Sensitivity to dielectric permittivities}

Let us consider different permittivities $\varepsilon_{\mathrm{r} 2}$ for substrate 2 , a ground plane at a distance $2 \mathrm{~mm}$ for $50 \%$ metal surface, at a higher frequency $(30.1 \mathrm{GHz})$, so that 15 modes are propagating. Results are reported in Table II for the TM case. Iteration number is still divided at least by 2.6 . Similar results are observed for the TE case.

\begin{tabular}{|c|c|c|c|c|c|c|}
\hline \multicolumn{2}{|c|}{$\varepsilon_{\mathrm{r} 2}$} & -20 & -10 & 1 & 10 & 20 \\
\hline \multirow{2}{*}{$\begin{array}{c}\text { No } \\
\text { Precond }\end{array}$} & $\begin{array}{c}\text { Niter } \\
\text { CPU time } \\
(\mathrm{ms})\end{array}$ & 90 & 94 & 120 & 215 & 233 \\
\hline \multirow{2}{*}{ Precond } & Niter & 26 & 30 & 45 & 57 & 62 \\
\cline { 2 - 7 } & $\begin{array}{c}\text { CPU time } \\
(\mathrm{ms})\end{array}$ & 89 & 104 & 191 & 270 & 308 \\
\hline Reduction factor Niter & 3.46 & 3.13 & 2.66 & 3.77 & 3.75 \\
\hline \multicolumn{2}{|c|}{ Reduction factor CPU } & 6.69 & 6.23 & 5.75 & 18.3 & 20.1 \\
\hline
\end{tabular}

TABLE II: ITERATION NUMBER FOR SEVERAL RELATIVE PERMITTIVITIES $\varepsilon_{\mathrm{R} 2}$.

\section{C-Sensitivity to frequency}

Let us consider different frequencies, a dielectric relative permittivity $\varepsilon_{\mathrm{r} 2}$ of 4.4 , a ground plane at a distance $2 \mathrm{~mm}$ for $50 \%$ metal surface. Results are reported in Table III for the TE case. Iteration number is still divided at least by 2.1 . The best couple value is not frequency dependent. Similar results are observed for the TM case. 


\begin{tabular}{|c|c|c|c|c|c|}
\hline \multicolumn{2}{|c|}{ Frequency $(\mathrm{GHz})$} & 0.3 & 3 & 30 & 300 \\
\hline \multirow{2}{*}{$\begin{array}{c}\text { No } \\
\text { Precond }\end{array}$} & \begin{tabular}{c} 
Niter \\
\cline { 2 - 6 } \\
\cline { 2 - 6 } \\
$(\mathrm{ms})$
\end{tabular} & 98 & 95 & 120 & 365 \\
\hline \multirow{4}{*}{ Precond time } & best $\left(\mathrm{a}_{1}, \mathrm{a}_{2}\right)$ & $(0,-1)$ & 689 & 1107 & 22663 \\
\cline { 2 - 6 } & Niter & 45 & 42 & 47 & 147 \\
\cline { 2 - 6 } & $\begin{array}{c}\text { CPU time } \\
(\mathrm{ms})\end{array}$ & 196 & 167 & 196 & 1837 \\
\hline \multicolumn{2}{|r|}{ Reduction factor Niter } & 2.17 & 2.26 & 2.55 & 2.46 \\
\hline \multicolumn{2}{|r|}{ Reduction factor CPU } & 3.67 & 4.12 & 5.64 & 12.33 \\
\hline
\end{tabular}

TABLE III: ITERATION NUMBER FOR SEVERAL FREQUENCIES.

\section{D-Operator Eigenvalue Analysis}

To understand the convergence improvement, the eigenvalues of the operators described in equations (4) and (5) are compared at $300 \mathrm{MHz}$ and $30.1 \mathrm{GHz}$ for $50 \%$ metal proportion without ground plane in vacuum and represented respectively in Figures 2 and 3. Even if preconditioned eigenvalues are better clustered than eigenvalues of the WCIP without preconditioner, no rule has been established to find out the best couples $\left(a_{1}, a_{2}\right)$ from the eigenvalue observation.

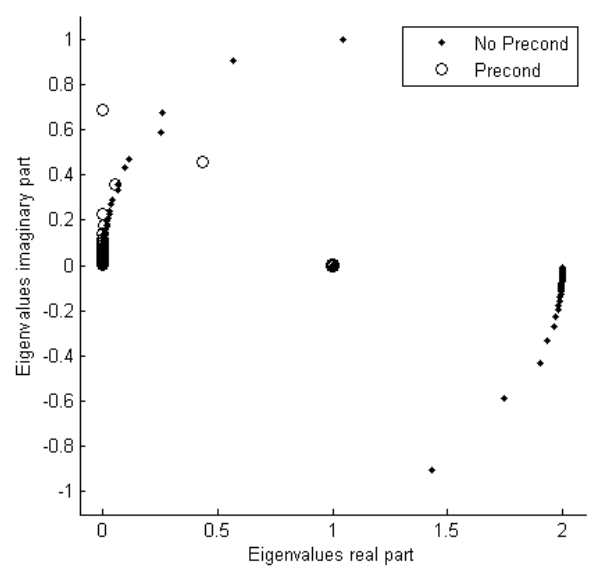

Fig. 2.Eigenvalues representation at 300MHz.

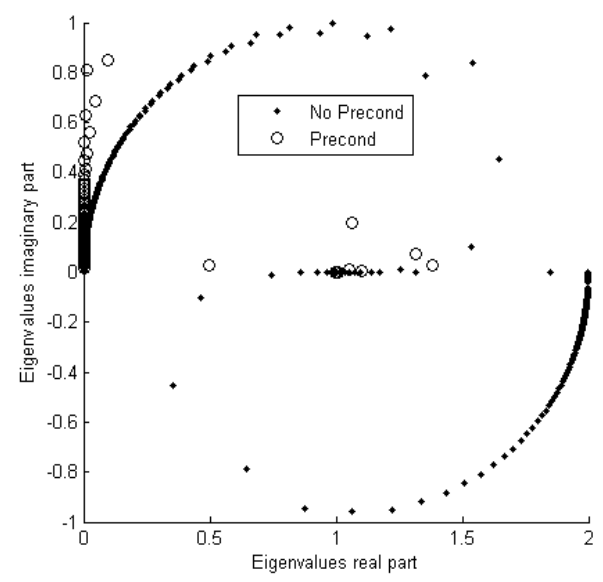

Fig. 3.Eigenvalues representation at $30.1 \mathrm{GHz}$.

\section{EXTENSION TO 2D PROBLEMS}

Preconditioner (8) is applied in the $2 \mathrm{~d}$ case with respect to (5) (TE and TM appear simultaneously). A square slot over an infinite dielectric $\left(\varepsilon_{\mathrm{r} 2}\right.$ of 4.4$)$ is illuminated by a z-polarized electric field at $3 \mathrm{GHz}$ composed of 20 modes. The number of unknowns is 160000 . Iteration number is observed for several metal proportions. For the sake of comparison, numerical experiments are reported in Table IV with and without preconditioner. Then its dual is studied: a square patch, results are reported in Table V. One can notice that the best couple does not depend on the metal proportion in both cases.

\begin{tabular}{|c|c|c|c|c|c|c|}
\hline \multirow{2}{*}{\multicolumn{2}{|c|}{$\begin{array}{l}\text { Metal proportion } \\
\text { No Precond Niter }\end{array}$}} & $19 \%$ & $36 \%$ & $50 \%$ & $75 \%$ & $90 \%$ \\
\hline & & 106 & 75 & 66 & 59 & 53 \\
\hline \multirow{2}{*}{ 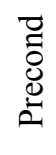 } & Niter & 69 & 37 & 33 & 33 & 5 \\
\hline & $\begin{array}{c}\text { best } \\
\left(a_{1}, a_{2}\right)\end{array}$ & $\begin{array}{l}(0.9, \\
-0.1)\end{array}$ & $\begin{array}{c}(0.9, \\
0)\end{array}$ & $\begin{array}{c}(0.9, \\
0)\end{array}$ & $\begin{array}{c}(0.9, \\
0)\end{array}$ & $\begin{array}{l}(1, \\
0)\end{array}$ \\
\hline \multicolumn{2}{|c|}{$\begin{array}{c}\text { Reduction factor } \\
\text { Niter }\end{array}$} & 1.53 & 2.02 & 2 & 1.78 & 10.6 \\
\hline
\end{tabular}

TABLE IV: PRECONDITIONER IN THE SLOT CASE.

\begin{tabular}{|c|c|c|c|c|c|c|}
\hline \multirow{2}{*}{\multicolumn{2}{|c|}{$\begin{array}{l}\text { Metal proportion } \\
\text { No Precond Niter }\end{array}$}} & $19 \%$ & $36 \%$ & $50 \%$ & $75 \%$ & $90 \%$ \\
\hline & & 48 & 48 & 50 & 69 & 96 \\
\hline \multirow{2}{*}{$\begin{array}{l}\vec{Z} \\
\text { Dू. } \\
\text { E. }\end{array}$} & Niter & 4 & 7 & 14 & 33 & 68 \\
\hline & $\begin{array}{l}\text { best } \\
\left(a_{1}, a_{2}\right)\end{array}$ & $\begin{array}{l}(0.4, \\
-0.6)\end{array}$ & $\begin{array}{l}(0.4, \\
-0.6)\end{array}$ & $\begin{array}{l}(0.4, \\
-0.6)\end{array}$ & $\begin{array}{l}(0.4 \\
-0.6)\end{array}$ & $\begin{array}{l}(0.4, \\
-0.4)\end{array}$ \\
\hline \multicolumn{2}{|c|}{$\begin{array}{c}\text { Reduction factor } \\
\text { Niter }\end{array}$} & 12 & 6.85 & 3.57 & 2.09 & 1.4 \\
\hline
\end{tabular}

TABLE V: PRECONDITIONER IN THE PATCH CASE.

\section{CONCLUSION}

A new physically-based right preconditioner is developed in this paper for the $1 \mathrm{~d}$ and $2 \mathrm{~d}$ WCIP. It allows at least to divide by 1.4 the iteration number compared to the initial Krylov subspace method without preconditioner for some examples. Several attempts to justify the adjustable parameter choice have been explored in the $1 \mathrm{~d}$ case, but no rules emerge from it. Extension to the $2 \mathrm{~d}$ case has been achieved on two examples and results are promising with a noticeable reduction of the number of iterations.

\section{REFERENCES}

[1] S. Wane, D. Bajon, H. Baudrand, P. Gamand "A new full-wave hybrid differential-integral approach for the investigation of multilayer structures including nonuniformly doped diffusion", IEEE MTT, vol. 53, $n^{\circ} 1$, pp. 200-213, January 2005.

[2] H. Baudrand, D. Bajon, "Equivalent circuit representation for integral formulatios' for electromagnetic problems", Int. Journal of Num. Modeling, vol. 15, n. 1, pp. 23-57, January 2002.

[3] N. Raveu, L. Giraud, H. Baudrand, "WCIP Acceleration", Microwave Conference Proceedings (APMC), pp. 971-974, December 2010.

[4] Y. Saad, Iterative methods for sparse linear systems, SIAM, 2003. 